\title{
Analysis and Solution of Typical Faults on the Video \& Teleconference System
}

\author{
LI Wen-cui, LUO Yu, DONG Kai-li, AN Zhi-yuan, WANG Chun-ying, ZHANG \\ Yong
}

Information \& Telecommunication Co. of State Grid Henan Electric Power Company, Zhengzhou 450052, China

email: elf8650@163.com

Keywords: Video \& teleconference system, Typical faults, Analysis and solution

\begin{abstract}
The video \& teleconference system is the important communications business platform of the company's production and operation. Annual State Grid and provincial network held more than a thousand times. The number of times is on the rise. The paper analysis the typical faults of video \& teleconference system, and introduces the solution of these faults.
\end{abstract}

\section{Introduction}

Video \& teleconference system is an information management system which has functions such as computer control, multimedia technology, network communication and video synthesis technology (as Fig.1).Because of the system MCU, terminals, switches and other equipment not Video \& teleconference system included in the real-time monitoring network elements, so when the teleconference system quality becomes poor, lost frames, such as Mosaic phenomenon, it is very hard to judge the reason, mostly rely on experience judgement and speculation [1-3].

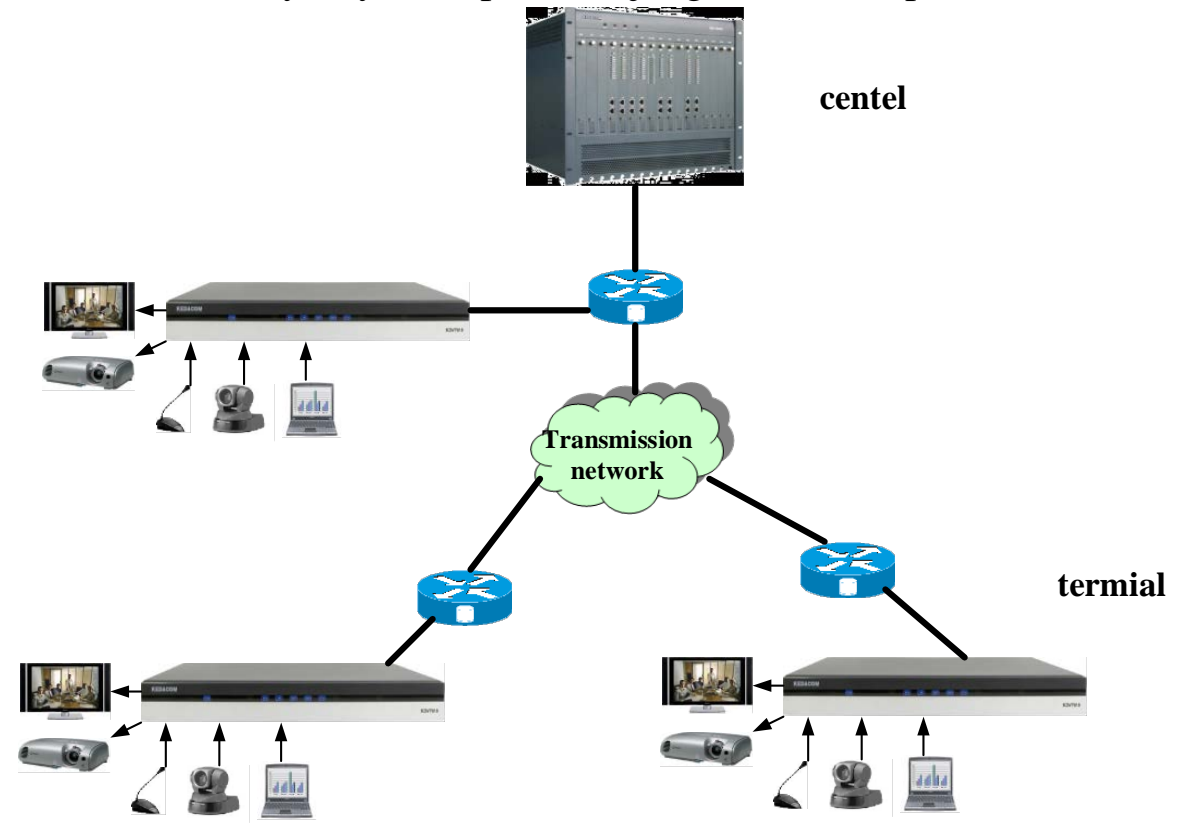

Fig.1 The structure of video \& teleconference system

\section{Typical Faults and the Solutions}

MCU Failure. MCU is the core equipment of teleconference system. The MCU equipment failure will affect the whole conference audio and video quality, even lead to its control of the entire conference system paralysis. MCU is a digital processing unit, usually installed in the network node. It is available for multiple sites meeting for communication between each other at the same time, the MCU can be realized in the digital domain audio, video, data and signal and digital signal mixed and switch, but does not affect the quality of the audio and video signals; If the MCU failure, it will 
affect the normal operation of the whole region TV conference [4-6].

Common failure phenomena of MCU: MCU does not start properly or can not be normal after the meeting started.

Reason of the failure. MCU function board failure causes that the MCU does not function properly.

Fault handling. The multipoint control unit has 17 function board slots. The main function board has the main processing board, the second floor exchange board, the system power board, stream forwarding board, digital mixing board, 5 decode board, E1 forwarding board. The KDV8000A MCU that the Provincial company currently uses supports hot backup of the main control board and hot-swappable board. The KDV8000A MCU supports hot backup of the main control board. If the main processing board fails, the MCU will automatically switch to the standby board. And then you can contact the manufacturer to provide technical support, and repair or replace the main processing board as soon as possible.

When the other board fails, you must first replace the faulty board and import the backup data into the new function board.

Image Failure. The Main Venue Can not Watch the Venue Image or the Local Image. Reason of the failure. (a) the video cable connector is loose; the video distributor is powered down; the power plug is loose or the power cord is aged. (b) video matrix call failure; terminal equipment failure. (c) camera failure.

Fault handling. (a)When the main venue can not watch the club image, you firstly confirm that whether there is a distant sub-venue image in the four-screen segmentation. If there is a distant sub-venue image in the four-screen segmentation, you can determine that the video matrix and the terminal is normal.Then the cause of the failure may be the video distributor power or wiring loosening. If the four-screen segmentation does not have a distant sub-field image, the cause of the failure may be the primary terminal failure, and the switch should be switched to the standby terminal. (b) When the main venue can not view the local image, you should firstly confirm that whether the four-screen segment has a local conference image. If the four-screen segment has a local conference image, the cause of the error may be that the video matrix is set incorrectly. And the matrix scheme should be recalled at this time. If the four-screen segmentation does not have the local venue image,you should check that whether the four screen has spare camera image, if the four screen has a spare camera image, you should switch the matrix scheme and call the backup camera image.

At one time, the operator checks the sub-venue according to the program before a meeting, the monitoring equipment has been normally display the screen. But the remote image of the main venue is still displayed as a laptop image. The operator determined that the matrix call was wrong. And after they recall the provincial main terminal video matrix , The main location of the remote image screen display normally.

The Phenomenon of Voice Equipment Failure. The main venue cannot hear the sound of the parallel sessions, and there are failures on the local voice equipment. Reason of the failure. (a) The conference TV terminal is failure, so the main venue cannot receive the distant sound. (b) The equipment of the main venue is failure, such as microphone, mixing consoles, power amplifier is failure.

Fault handling. (a) When the main venue cannot hear the sound of the parallel sessions, the first step is to switch the conference call through the mixing consoles to ensure the meeting, and then check the reasons why the voice is failure. (b) When there are faults on the local sound, first of all, confirming that whether the microphone is on or not, and at the same time, confirming that whether the microphone chuck is loose or not. Then, check out whether the mixer is normal. If there are faults on themixer, enable the backup mixer immediately. And if the mixer runs normally, the operator should secondly check that whether the power amplifier is normal. If there are faults on the power amplifier, enable the backup power amplifier immediately.

Classic Case. During a scheduled meeting, the main venue cannot hear the speaker's voice when a power plant speaking, but can watch the scene of the power plant normally. Voice of Thepower 
plant was delivered to the main conference by switching on the mixer conference call as soon as possible, which makes the meeting held normally.

Other Failure. Conference terminal is the important equipment in teleconference system, terminal failure will affect the quality in the meeting audio and video signal or lead to interruption of audio and video transmission[4]. Terminal equipment failure relative MCU the smaller effective, generally reflected in: terminal image output, the local voice, terminal software cannot upgrade, camera control failure and unable to remote control remote cameras [7-9].

Conference system peripherals mainly includes camera, microphone, audio and video matrix, display devices, etc. Mainly used for local audio and video input and output control. Peripheral equipment failure will affect the quality of audio and video signal or lead to interruption of audio and video transmission. And other failures are shown as Tab.1.

Tab.1 The solutions of the daily malfunction

\begin{tabular}{|c|c|c|}
\hline Fault phenomenon & Cause analysis & Solution \\
\hline \multirow{3}{*}{$\begin{array}{l}\text { The gateway is } \\
\text { normal, the terminal } \\
\text { is impassable. }\end{array}$} & Terminal address has been changed & $\begin{array}{l}\begin{array}{l}\text { Reconfiguration } \\
\text { (Ipaddress) }\end{array} \\
\end{array}$ \\
\hline & $\begin{array}{l}\text { Nic light is not bright, the cable } \\
\text { connection is wrong }\end{array}$ & Check the cable connection \\
\hline & The network ports of terminal down & Restart/openthe terminal \\
\hline \multirow{3}{*}{$\begin{array}{l}\text { The gateway is } \\
\text { normal. The terminal } \\
\text { can ping, but cannot } \\
\text { connect. }\end{array}$} & $\begin{array}{l}\text { Terminal extension (E.164) and the } \\
\text { terminal code change. It isn't agree } \\
\text { with the legal information in the GK } \\
\text { registered. }\end{array}$ & $\begin{array}{l}\text { Check the terminal } \\
\text { configuration (the } \\
\text { terminal extension and the } \\
\text { terminal code) }\end{array}$ \\
\hline & Terminal BUG & Restartthe terminal \\
\hline & The terminal is visible. & $\begin{array}{l}\text { Converts a terminal to a } \\
\text { desktop terminal or } \\
\text { terminals in the meeting } \\
\text { room. }\end{array}$ \\
\hline \multirow[t]{2}{*}{$\begin{array}{l}\text { The gateway is } \\
\text { impassable. }\end{array}$} & $\begin{array}{llll}\text { Protocol converter doesn't run } \\
\text { properly }\end{array}$ & $\begin{array}{l}\text { Check the converter light/ } \\
\text { Check the switch/ Reset the } \\
\text { protocol converters/ } \\
\text { Change the protocol } \\
\text { converters }\end{array}$ \\
\hline & $2 \mathrm{M}$ transmission line isn’t normal & $\begin{array}{l}\text { Check the } 2 \mathrm{M} \text { transmission } \\
\text { line }\end{array}$ \\
\hline $\begin{array}{l}\text { The gateway and the } \\
\text { terminal are normal, } \\
\text { but unable to sign up } \\
\text { for network }\end{array}$ & The network is & $\begin{array}{l}\text { Find the reaction solution } \\
\text { from the network } \\
\text { administrator }\end{array}$ \\
\hline \multirow{2}{*}{$\begin{array}{l}\text { Individual terminals } \\
\text { are down when the } \\
\text { meeting is doing on }\end{array}$} & $\begin{array}{l}\text { Network packet loss rate from } \\
\text { terminals to GK and MCU }\end{array}$ & $\begin{array}{l}\text { Check the quality of } \\
\text { transmission network }\end{array}$ \\
\hline & $\begin{array}{l}\text { The BUG of the MCU result the } \\
\text { failure }\end{array}$ & $\begin{array}{l}\text { Reflect to the } \\
\text { manufacturers }\end{array}$ \\
\hline \multirow{3}{*}{$\begin{array}{l}\text { The terminal image is } \\
\text { not good }\end{array}$} & Lost packets of codec training & $\begin{array}{l}\text { Terminal restart the reset } \\
\text { link }\end{array}$ \\
\hline & $\begin{array}{l}\text { Terminal handling capacity and the } \\
\text { rate does not match }\end{array}$ & Modify the meeting rate \\
\hline & Network performance is not good & $\begin{array}{l}\text { The delay requirement } \\
\text { can't exceed 50ms, and the } \\
\text { packet loss rate required to } \\
\text { zero. }\end{array}$ \\
\hline
\end{tabular}




\section{Conclusion}

The video \& teleconference system is the important communications business platform of the company's production and operation. Annual State Grid and provincial network held more than a thousand times. The number of times is on the rise. So how to recovery failures in a short period is important to maintainer. The paper analysis the typical faults of video \& teleconference system, and introduces the solution of these faults.

\section{References}

[1] Ookuzu H., Shibata Y.. Implementation and Performance Evaluation of a New Teleconference System by Giga Ether Based Omni-directional Video Cameras[C], IEEE International Conference on Distributed Computing Systems Workshops. IEEE Computer Society, 2009:374-379.

[2] Gao J.J, Wang Q.M., Wang L.J., et al. Design and Application of SGCC Main-standby Mode Teleconference System[J]. Electric Power Information \& Communication Technology, 2014.

[3] Saysell E., Routley C.. Telemedicine in community-based palliative care: evaluation of a videolink teleconference project.[J]. International Journal of Palliative Nursing, 2003, 9(11):489.

[4] Shibuichi D., Tanaka T., Terashima N., et al. Teleconferencing system using virtual camera[C],Electronic Imaging. International Society for Optics and Photonics, 2000:350-361.

[5] Hao Y.U.. Study on the upgrading of teleconference system in Anhui power system[J]. Telecommunications for Electric Power System, 2008.

[6] Zhang S.J., Wang R.Q., Liu Y., et al. Discussion on Shanxi Electric Power Meeting-television Operation Manner[J]. Shanxi Electric Power, 2009.

[7] Li Yongjie, Chang Ying, Wang Xin, etc. Henan TV video conference television system architecture and analysis [J]. Television Technology, 2014, 38 (19): 221-224.

[8] Yu Jing, Zhou Guoyao, Hu Y.. Method and system for video quality detection: CN, CN 103281559 A [P]. 2013.

[9] Gu Chong, Si Zhanjun. Application of video quality evaluation method [C] // 2012 China Printing and Packaging Academic Conference. 